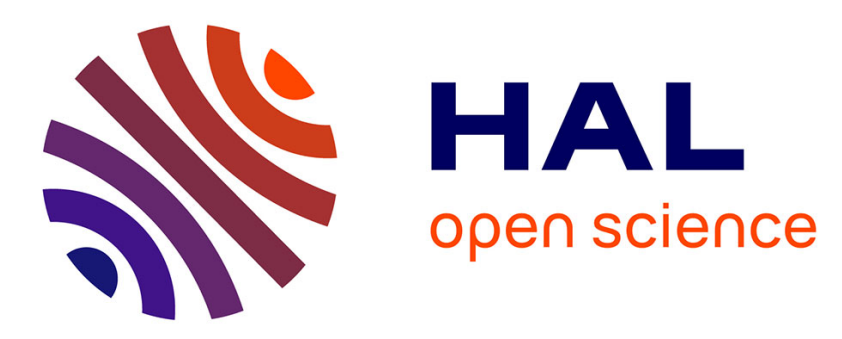

\title{
Semi-mechanistic population pharmacokinetic/pharmacodynamic model for neutropenia following therapy with the Plk-1 inhibitor BI 2536 and its application in clinical development
}

Elena Soto, Alexander Staab, Christiane Tillmann, Dirk Trommeshauser, Holger Fritsch, Gerd Munzert, Iñaki F. Trocóniz

\section{To cite this version:}

Elena Soto, Alexander Staab, Christiane Tillmann, Dirk Trommeshauser, Holger Fritsch, et al.. Semimechanistic population pharmacokinetic/pharmacodynamic model for neutropenia following therapy with the Plk-1 inhibitor BI 2536 and its application in clinical development. Cancer Chemotherapy and Pharmacology, 2010, 66 (4), pp.785-795. 10.1007/s00280-009-1223-2 . hal-00553737

\section{HAL Id: hal-00553737 \\ https://hal.science/hal-00553737}

Submitted on 9 Jan 2011

HAL is a multi-disciplinary open access archive for the deposit and dissemination of scientific research documents, whether they are published or not. The documents may come from teaching and research institutions in France or abroad, or from public or private research centers.
L'archive ouverte pluridisciplinaire HAL, est destinée au dépôt et à la diffusion de documents scientifiques de niveau recherche, publiés ou non, émanant des établissements d'enseignement et de recherche français ou étrangers, des laboratoires publics ou privés. 


\title{
Semi-mechanistic population pharmacokinetic/pharmacodynamic model for neutropenia following therapy with the Plk-1 inhibitor BI 2536 and its application in clinical development
}

\author{
Elena Soto $\cdot$ Alexander Staab $\cdot$ Christiane Tillmann • \\ Dirk Trommeshauser • Holger Fritsch • \\ Gerd Munzert • Iñaki F. Trocóniz
}

Received: 3 August 2009/Accepted: 13 December 2009/Published online: 9 January 2010

(C) Springer-Verlag 2010

\begin{abstract}
Purpose (1) To describe the neutropenic response of BI 2536 a polo-like kinase 1 inhibitor in patients with cancer using a semi-mechanistic model. (2) To explore by simulations (a) the neutropenic effects for the maximum tolerated dose (MTD) and the dose at which dose-limiting toxicity occurred, (b) the possibility to reduce the cycle duration without increasing neutropenia substantially, and (c) the impact of the initial absolute neutrophil count (ANC) on the degree of neutropenia for different doses.

Experimental design BI 2536 was administered as intravenous infusion over $60 \mathrm{~min}$ in the dose range from 25 to $250 \mathrm{mg}$. Three different administration schedules were explored: (a) day 1, (b) days 1, 2, and 3 or (c) days 1 and 8 within a 3 week treatment cycle.

BI 2536 plasma concentrations and ANC obtained during the first treatment cycle from 104 patients were analysed using the population approach with NONMEM VI.

Results Neutropenia was described by a semi-mechanistic model resembling proliferation at the stem cell compartment, maturation, degradation, and homeostatic regulation. BI 2536 acts decreasing proliferation rate.
\end{abstract}

Electronic supplementary material The online version of this article (doi:10.1007/s00280-009-1223-2) contains supplementary material, which is available to authorized users.

E. Soto · I. F. Trocóniz ( $\square)$

Department of Pharmacy and Pharmaceutical Technology;

School of Pharmacy, University of Navarra,

31080 Pamplona, Spain

e-mail: itroconiz@unav.es

A. Staab - C. Tillmann - D. Trommeshauser · H. Fritsch .

G. Munzert

Boehringer Ingelheim Pharma GmbH \& Co. KG, Biberach, Germany
Simulations showed that (1) all MTD doses showed an acceptable risk of neutropenia, (2) when BI 2536 is given as $200 \mathrm{mg}$ single administration, cycle duration can be reduced from 3 to 2 weeks, and (3) baseline ANC might be considered to individualise the dose of $\mathrm{BI}$ 2536.

Conclusions A semi-mechanistic population model was applied to describe the neutropenic effects of BI 2536. The model was used for simulations to support further clinical development.

Keywords BI 2536 · Plk-1 inhibitor · Population model · NONMEM $\cdot$ Neutropenia

\section{Introduction}

Cell-cycle-targeted therapies represent a promising novel approach in cancer therapy. Mitotic kinases regulating cell division and its checkpoints are considered particularly attractive targets for new therapies. The Polo family of mitotic kinases have been identified as important regulators of cell division [1]. Polo-like kinase 1 (Plk-1) controls several key steps in the passage of cells from G2 to M phase and through the $M$ phase [2]. Inhibition of Plk-1 results in cell-cycle arrest with subsequent induction of apoptosis, making Plk-1 an attractive target for novel therapeutic approaches in cancer.

BI 2536 is an inhibitor of Polo-like kinase 1 (Plk-1) currently in clinical development. This compound induces cell-cycle arrest, apoptosis, and tumour shrinkage at tolerable doses in preclinical tumour models [3]. In the clinical setting, these effects may hopefully translate into tumour remissions in patients without further treatment options [4]. 
The most relevant side effect of BI 2536 administration is expected to be a transient inhibition of proliferation of normal dividing cells in mucosal tissue and bone marrow. Neutropenia is currently the most common toxicity associated with the administration of several cytotoxic anticancer drugs [5] and proved to be the dose-limiting toxicity in Phase I trials for BI 2536 [4]. Thus, establishing the relationship between drug concentrations and neutropenia for the optimisation of doses and administration schedules is invaluable.

Design of Phase II studies of new anticancer compounds is usually based on the pharmacokinetic and the side effect profiles obtained during small Phase I studies in patients with advanced cancer. Efficacy data are often limited in these studies due to inclusion of different tumour types and the advanced disease state of the patients [6]. Over the last years, the time course of neutropenia or other drug related haematological toxicities have been modelled linking the pharmacokinetic (PK) model with a model that describes the haematological toxicity [7-11]. Among these approaches, the model developed by Friberg et al. [9] has been applied repeatedly to describe the time course of myelosuppression after administration of several cytotoxic anticancer drugs [12-19]. In addition, this model has successfully been applied in the scaling of the time course of myelosuppression from rat data to patients showing its usefulness in the drug development process [20].

The first objective of this analysis was to describe the pharmacokinetic properties of BI 2536 and to correlate the PK with the neutropenic effects of BI 2536 using a semimechanistic modelling approach.

In the design of clinical trials, the choice of the appropriate dose, dosing schedule, sampling, and patient inclusion and exclusion criteria have to be considered carefully. Given the fact that Phase I clinical studies in oncology generally involve a very small number of patients with heterogeneous advanced cancer per dose level and that a very reduced number of different dosing and sampling schedules are considered, it would be of great interest to evaluate the typical neutropenic response in larger (simulated) populations of patients with cancer receiving BI 2536 under different clinical scenarios.

Therefore, the second objective of the current work was to use the PK/PD model developed for BI 2536 to explore using simulations (1) the neutropenic effects for maximum tolerated dose (MTD) and the dose at which dose-limiting toxicity (DLT) occurred (Sim I), (2) the possibility of reducing the dosing interval from the original 3-2 weeks without increasing neutropenia substantially (Sim II), and (3) the degree of neutropenia for different doses depending on the initial absolute neutrophil count (ANC) level (Sim III).

\section{Methods}

Patient population

Data from two multicentre, open label, dose escalation, Phase I clinical trials in patients with advanced cancer were used for the current analysis. All participants provided written informed consent consistent with ICH-GCP (International conference on Harmonisation of Technical Requirements for Registration of Pharmaceuticals for Human Use-Good Clinical Practice) and local legislation, once the nature and the intention of the investigation were fully explained. The studies were performed in accordance with the Declaration of Helsinki and were approved by the institutional review board of the ethics committee at each study site.

Data from 104 cancer patients with confirmed diagnosis of advanced, non-resectable, and/or metastatic solid tumours who had failed conventional treatment or for whom no therapy of proven efficacy existed were available for analysis. Additional information about the study e.g. inclusion and exclusion criteria has been reported elsewhere [4].

Study design

\section{Drug administration}

Patients were administered BI 2536 at doses ranging from 25 to $250 \mathrm{mg}$ as intravenous infusion over $60 \mathrm{~min}$ as part of a 21-day treatment cycle. BI 2536 was not dosed per $\mathrm{kg}$ or per $\mathrm{m}^{2}$, all patients in each dose group received the same total drug amount. For example, and on the basis of the mean weight and body surface area values in the studied population $\left[73 \mathrm{~kg}\right.$ and $1.85 \mathrm{~m}^{2}$, respectively (Supplementary Table I)], the $250 \mathrm{mg}$ dose corresponds to $3.42 \mathrm{mg} / \mathrm{kg}$, and $135 \mathrm{mg} / \mathrm{m}^{2}$, respectively.

Subjects on the first study received doses either on Day 1 (Schedule A) or on Days 1, 2, and 3 (Schedule B). Subjects in the second study received doses on Days 1 and 8 (Schedule C). None of the patients included in the analysis had received treatment with granulocyte colonystimulating factor (G-CSF).

\section{Pharmacokinetic measurements}

Venous blood samples $(4 \mathrm{~mL})$ were sequentially drawn during the administration days, and up to $168 \mathrm{~h}$ after drug administration. Assay of BI 2536 in plasma. Plasma concentrations of BI 2536 were determined using a fully validated high performance liquid chromatography tandemmass spectrometry (HPLC-MS/MS) method using 
electrospray ionisation in the positive ion mode and $\left[\mathrm{D}_{3}\right]$ BI 2536 as internal standard. Chromatography was achieved on an analytical reversed phase HPLC column with gradient elution.

The calibration curves of undiluted plasma samples were linear over the range of concentrations from 0.500 to $500 \mathrm{ng} / \mathrm{mL}$ of BI $2536 \mathrm{BS}$ using a plasma volume of 100 or $50 \mu \mathrm{L}$. The method showed inaccuracy and imprecision (CV) values below $11 \%$. The lower limit of quantification was validated to be $0.500 \mathrm{ng} / \mathrm{mL} \mathrm{BI} 2536 \mathrm{BS}$, whereas the upper limit of quantification was $500 \mathrm{ng} / \mathrm{mL}$ of BI $2536 \mathrm{BS}$ in plasma samples.

\section{Absolute neutrophil count measurements}

Absolute neutrophil count (ANC) was determined in blood by standard clinical haematology methods.

The characteristics of the patient population from both clinical trials used for the current analysis (classified by schedule), dosing information, and the complete sampling design for pharmacokinetic and for ANC analysis are presented in Supplementary Tables 1 and 2 and Supplementary Fig. 1, respectively.

Data analysis

The modelling was performed sequentially using the population modelling approach. Only data from cycle one was available for the analysis. First, the PK model was developed and then the time course of ANC was modelled using for each patient the respective individual model predicted PK parameters.

The First Order Conditional Estimation (FOCE) method with the option INTERACTION implemented in the software NONMEM version VI [21] was used for parameter estimation. Graphical representations and generation of simulation results were done with the S-PLUS ${ }^{\circledR} 6.1$ Professional Edition (Copyright 1988, 2002 Insightful Corp.) software and R software.

\section{Pharmacokinetic model}

The time course of BI 2536 plasma concentrations was described by compartmental models parameterized in apparent volumes of distribution, intercompartmental clearances and elimination clearance. One-, two- and threecompartment models were tested. As the dose levels administered ranged from 25 to $250 \mathrm{mg}$, models accounting for concentration dependencies in PK were also investigated. Initially the amount of BI 2536 in each of the compartments of the model is equal to 0 .

\section{Semi-mechanistic model for absolute neutrophil count}

The semi-mechanistic pharmacokinetic/pharmacodynamic (PK/PD) model previously published by Friberg et al. [9] were initially fitted to the ANC versus time data using the individual PK parameters determined by the PK model. In short, it consisted of a system dependent and a drug dependent part. The system dependent part resembled in a simplified manner the underlying physiological processes determining the ANC in the circulation: (1) proliferation at the stem cell compartment, (2) maturation, represented in the model by three transit compartments, (3) degradation, and (4) homeostatic regulation: $1-4$ can be described by the first-order rate constant $\left(k_{\text {prol }}\right)$, the mean transit time (MTT), the first-order rate constant of degradation $\left(k_{\text {circ }}\right)$, and the feedback parameter $(\gamma)$. $\operatorname{Circ}_{0}$ represents ANC at baseline. In the model $k_{\text {prol }}=k_{\text {circ }}=k_{\mathrm{TR}}$, where $k_{\mathrm{TR}}$ is the first-order rate constant governing the transfer of immature cells between the transit compartments computed as $(n+1) / \mathrm{MTT}, \mathrm{n}$, being the number of transit compartments included in the model. Before drug treatment, the initial conditions in the stem cell, transit, and circulating compartments are the same and equal to $\mathrm{Circ}_{0}$. The drug effect was represented by the parameter slope and included in the model as follows: $k_{\text {prol }} \times(1$-slope $\times \mathrm{C})$, where $\mathrm{C}$ was the predicted BI 2536 plasma concentration. The semi-mechanistic PKPD model is schematically and mathematically represented in Fig. 1.

Variants to the Friberg et al. [9] model including (1) the sigmoid $E_{\mathrm{MAX}}$ model to describe the drug effects, (2) the incorporation of an effect compartment model as it has been reported previously [8, 19], (3) a zero order process to described the rate of proliferation in the stem cell compartment [8], (4) different number of transit compartments, (5) and the use of a different model to account for the feedback mechanism as suggested by Panetta et al. [10] were also fit to the ANC versus time data.

Inter-patient variability (IPV) was tested for significance in all model parameters and was modelled exponentially. Residual variability was described using a combined (additive and proportional) random effect model. If during the analyses one of the components of the combined random effect model was found to be negligible it was deleted.

\section{Model selection}

The minimum value of the objective function provided by NONMEM, approximately equal to $-2 \times \log$ (likelihood) [-2LL], was used as a guide during the model development. For two nested models a decrease in 3.84 or 6.63 points in $-2 \mathrm{LL}$ for an extra parameter was considered significant at the 5 or $1 \%$ level, respectively. Since some of the models compared were not nested, -2LL was not used 
Fig. 1 PK and PK/PD models selected for BI 2536 after intravenous infusion(s) to patients. CL, total clearance; $Q_{2}$ and $Q_{3}$, intercompartmental clearances; $V_{1,2,3}$, volumes of distribution of the central, shallow, and deep compartments, respectively. MTT, mean transit time; $k_{\text {prol }}$, first-order rate constant of proliferation; $k_{\text {circ }}$, first-order rate constant degradation of circulating cells; $k_{\mathrm{TR}}$, first-order rate constant of transit; $\mathrm{Circ}_{0}$, ANC at baseline; $\gamma$, feedback parameter; C, BI 2536 plasma concentrations

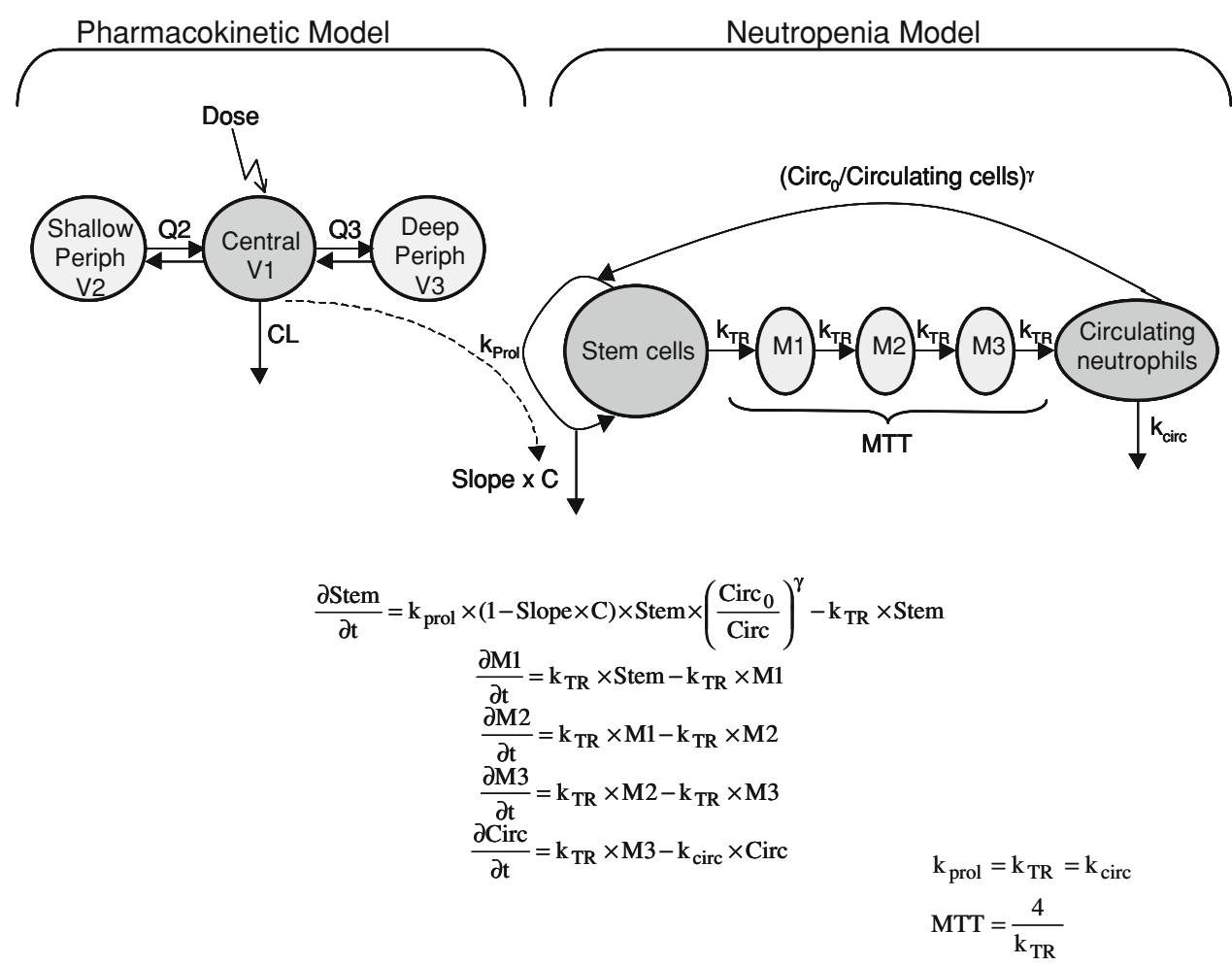

directly for comparative purposes, and the value of the Akaike information criteria (AIC) [22] computed as $-2 \mathrm{LL}+2 \times \mathrm{Np}$, where $\mathrm{Np}$ is the number of the parameters in the model, was used instead.

In addition to the $-2 \mathrm{LL}$ or AIC values, parameter precision, expressed as coefficient of variation $[\mathrm{CV}(\%)]$, and computed as the ratio between the standard error and the model parameter estimate, multiplied by 100 , and the visual inspection of the goodness-of-fit plots, which shows model performance regarding existing data, were also used as criteria for model selection. The model with the lowest $-2 \mathrm{LL}$ or AIC value and acceptable parameter precision supported by the goodness-of-fit plots was finally selected.

\section{Covariate model selection}

The list of individual characteristics that were explored for covariate effects is presented in Supplementary Table 1. Once a model providing an adequate description of the data without the incorporation of covariates was selected, patient characteristics were explored for significance using the generalised additive model (GAM) approach [23] implemented in the software Xpose version 3 [24]. The covariates initially selected during the GAM analysis were further tested for significance in NONMEM using the forward inclusion and backward elimination approach. During the forward inclusion and backward elimination, the significance levels used were 5 and $1 \%$, respectively.

\section{Model evaluation}

The selected PK/PD model was further explored by visual and numerical predictive checks.

\section{Visual predictive check $^{1}$}

For the maximum tolerated dose (MTD) of each dosing schedule, A, B, or C, one thousand PK/PD time profiles were simulated. Then the 5th, 50th, and 95th percentiles of simulated data were calculated per sampling time point and represented together with the raw data.

\section{Numerical predictive check}

One thousand datasets having the same characteristics as the original dataset were simulated, and for each dataset, the percentage of patients showing neutropenia grade 4 , the mean ANC at nadir, and the mean time to nadir were computed. Then, the overall mean was calculated for each of the descriptors using the thousand values and compared to the same descriptors calculated from the raw data.

\section{Model-based simulations to support clinical development}

During simulations, the following clinical descriptors were calculated: (1) percentage of patients showing neutropenia

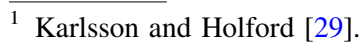


grade $4(\% \mathrm{G} 4)$, (2) percentage of patients showing neutropenia grade 4 for more than 7 consecutive days (\%G4 > 7 days), (3) time to nadir after the start of each treatment cycle $\left(T_{\text {nadir }}\right)$, and (4) time to recover to baseline ANC after the start of each cycle of treatment $\left(T_{\text {recover }}\right)$.

Always ten thousand ANC versus time profiles were generated for each simulated condition taking into account interindividual variability together with parameter uncertainty. The duration of the intravenous infusion was always $1 \mathrm{~h}$. For simulations Sim I and Sim II, two different dose levels (low and high) were used for each dosing schedule (Schedule A to $\mathrm{C}$ in Supplementary Table II). Schedules $\mathrm{A}_{\text {Low }}, \mathrm{B}_{\text {Low }}, \mathrm{C}_{\text {Low }}$ and $\mathrm{A}_{\text {High }}, \mathrm{B}_{\text {High }}, \mathrm{C}_{\text {High }}$ correspond to MTD and doses at which DLT occurred, respectively. For Simulation III, only Schedule A was evaluated. As in the original clinical trials, in each simulation, dose group all subjects were assumed to receive the same fixed dose regardless body weight and body surface area.

Sim I The neutropenic effects $(\% \mathrm{G} 4, \% \mathrm{G} 4>7$ days, $T_{\text {nadir }}$ and $T_{\text {recover }}$ ) for the MTD and doses at which DLT occurred were studied using simulated ANC versus time profiles

Sim II ANC versus time profiles were simulated for each of the MTD and doses at which DLT occurred considering three cycles of treatment in which BI 2536 was administered every 2-3 weeks. The \%G4 was then calculated for each cycle

Sim III ANC versus time profiles were simulated after administration of BI 2536 doses ranging from 100 to $300 \mathrm{mg}$ according to Schedule A, and ANC levels at baseline from 1 to $12 \times 10^{9} / \mathrm{L}$, resembling the range observed in the population studied, and \%G4 was then calculated

\section{Results}

A total of 1,360 plasma concentrations and 752 ANCs obtained from 104 patients during the first cycle of treatment were available to develop the PK and PK/PD model.

\section{Pharmacokinetic model}

A three-compartment model described the PK data significantly better than a one or a two compartment model $(P<0.01)$. IPV was included on the total plasma clearance $(\mathrm{CL})$, the apparent volume of distribution of the central $\left(V_{1}\right)$, and the apparent volume of the peripheral compartments $\left(V_{2}\right.$ and $\left.V_{3}\right)$. The off-diagonal elements of the $\Omega$ variance-covariance matrix were not supported by the data $(P>0.05)$. Residual variability was best described with a model combining additive and proportional terms.

Table 1 shows the population PK model estimates of BI 2536 after intravenous infusion. The parameter precision was high with $\mathrm{CV}$ less than $20 \%$ for the typical model estimates. IPV was moderate (CL) to high $\left(V_{3}\right)$. The calculated $\eta$-shrinkage was less than $15 \%$ with the exception of $V_{2}(31.2 \%)$ indicating that empirical Bayesian Estimates and results from GAM analysis were reliable.

During model development, no indication for dosedependent PK was found suggesting linear PK. Although gender, body mass index, height, age, and smoking and alcohol status were selected from the GAM approach as significant covariates, none of these were found to have a significant effect on the PK characteristics once they were incorporated in the NONMEM model $(P>0.05)$.

Figure $2 \mathrm{a}$ in supplementary material shows two goodness-of-fit plots confirming the adequacy of the model in describing the typical and individual PK profiles; the latter was additionally supported by the low value of $\%$ $\varepsilon$-shrinkage [25]. The individual and typical BI 2536 plasma concentration versus time profiles for six subjects chosen at random (Fig. 2a), and the results from the Visual

Table 1 Pharmacokinetic and pharmacodynamic parameters for BI 2536

\begin{tabular}{lcll}
\hline Parameter & Estimate & IPV & $\eta$-shrinkage \\
\hline Pharmacokinetics & & & \\
CL $(\mathrm{L} / \mathrm{h})$ & $69.9(4.7)$ & $49(27.9)$ & 3.8 \\
$V_{1}(\mathrm{~L})$ & $69.1(9.8)$ & $79(25.3)$ & 12.5 \\
$Q_{2}(\mathrm{~L} / \mathrm{h})$ & $48.5(7.3)$ & $\mathrm{Ne}$ & $\mathrm{Na}$ \\
$V_{2}(\mathrm{~L})$ & $1,350(9.7)$ & $45(27.7)$ & 31.6 \\
$Q_{3}(\mathrm{~L} / \mathrm{h})$ & $108(10.5)$ & $\mathrm{Ne}$ & $\mathrm{Na}$ \\
$V_{3}(\mathrm{~L})$ & $190(15.5)$ & $134(21.8)$ & 6.2 \\
Additive error $(\mathrm{ng} / \mathrm{mL})$ & $0.410(36.6)$ & $\mathrm{Na}$ & $\mathrm{Na}$ \\
Proportional error $(\%)$ & $39.2(8.7)$ & $\mathrm{Na}$ & $\mathrm{Na}$ \\
Pharmacodynamics & & & \\
Circ ${ }_{0}\left(\right.$ cells $\left.\times 10^{9} / \mathrm{L}\right)$ & $4.96(4.0)$ & $421(15.3)$ & 3.3 \\
MTT (h) & $107(3.8)$ & $22(46.4)$ & 20.9 \\
Slope $(\mathrm{mL} / \mathrm{ng})$ & $0.0147(8.6)$ & $65(24.3)$ & 19.1 \\
$\gamma$ & $0.161(5.9)$ & $\mathrm{Ne}$ & $\mathrm{Na}$ \\
Additive error & $0.278(47.8)$ & $\mathrm{Na}$ & $\mathrm{Na}$ \\
$\left(\right.$ cells $\left.\times 10^{9} / \mathrm{L}\right)$ & & & $\mathrm{Na}$ \\
Proportional error $(\%)$ & $21.1(9.0)$ & $\mathrm{Na}$ & \\
\hline
\end{tabular}

Parameters are listed together with the coefficient of variation $[\mathrm{CV}(\%)]$ in parenthesis. $C L$, total plasma clearance; $V_{1}$, volume of distribution in the central compartment; $V_{2}$ and $V_{3}$, volume of distribution in the peripheral compartments; $Q_{2}$ and $Q_{3}$, Intercompartmental clearances; $\operatorname{Circ}_{0}$, basal ANC; MTT, maturation mean transit time; $\gamma$, feedback parameter; $I P V$, inter-patient variability expressed as $\mathrm{CV}(\%) ; \mathrm{Ne}$, not estimated; $\mathrm{Na}$, not applicable 
Fig. 2 a BI 2536 plasma concentrations versus time profiles for six randomly selected patients. Symbols, individual values; grey solid lines, individual model predictions; dashed lines, typical population model predictions b Results from the visual predictive check. Solid lines represent the median profiles; shadowed areas cover the $90 \%$ of the simulated BI 2536 plasma concentrations
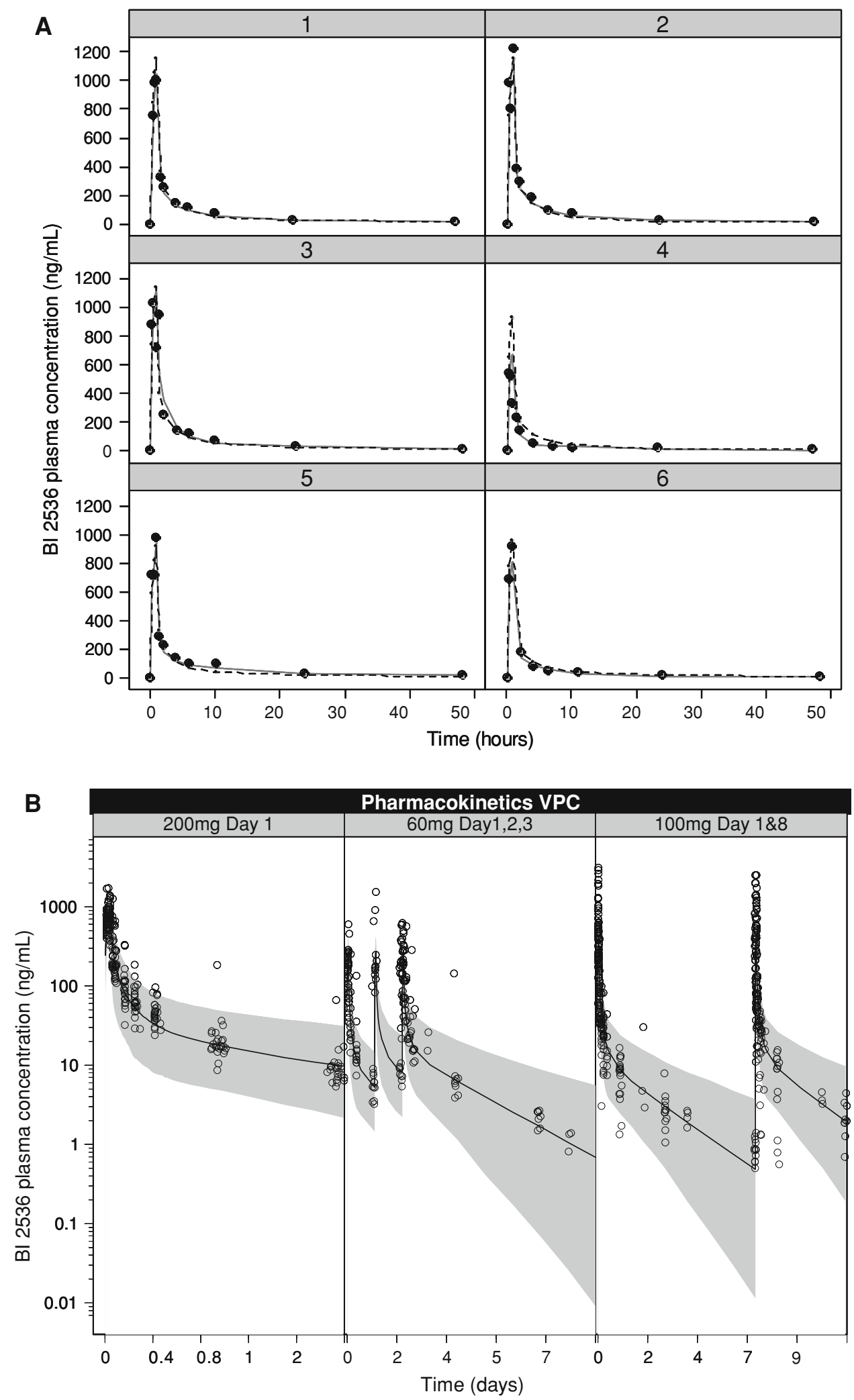

Predictive Check (Fig. 2b) indicate that the selected PK model is supported by the data and provides a good description of the mean tendencies and of the variability of the raw data.

Semi-mechanistic model for absolute neutrophil count

The model originally proposed by Friberg et al. [9] described the data very well and provided model parameter 
estimates with good precision (Table 1). The data supported the estimation of IPV for $\mathrm{Circ}_{0}$, MTT, and slope. Residual variability was best described by a combined random effect model. The use of a sigmoid $E_{\mathrm{MAX}}$ model, the addition of an effect compartment, and increasing the number of transit compartments did not improve the model performance significantly $(P>0.05)$. However, describing the proliferation in the stem cell compartment by a zero order rate process, using a different model to account for the feedback effects [10], and decreasing the number of transit compartments resulted in a worse fit.

During the GAM analysis, gender was selected as covariate for MTT, and body surface area (BSA), administration schedule $(\mathrm{SCH})$, and also gender, were selected as covariates for the slope parameter. In the final covariate, selection process performed in NONMEM, $\mathrm{BSA}, \mathrm{SCH}$, and gender gave similar decreases in $-2 \mathrm{LL}$ [14.3-16.7] $(P<0.01)$; however, none of those three covariates reduced the estimate of IPV on slope by more than $5 \%$.

Simulations were performed to explore the impact of dosing schedule on the time course of ANC; the results obtained indicated that the $\mathrm{SCH}$ effects were negligible. BSA and gender were highly correlated and therefore they are confounded covariates. The slope estimates suggested that female patients or subjects with lower BSA were more sensitive to BI 2536 neutropenic effects. Based on recent results obtained in a Phase II study (data not shown) that did not support the gender or BSA effects on slope, no covariates were included in the model.

Table 1 lists the population parameter estimates corresponding to the selected model. All parameters were estimated with adequate precision. The calculation of $\eta$ - and $\varepsilon$-shrinkage gave values $\leq 21 \%$.

The goodness-of-fit plots (Supplementary Fig. 2B), the individual and typical ANC versus time profiles for eight subjects chosen at random (Fig. 3a) and the results from the Visual Predictive Check (Fig. 3b) indicate that the selected model for ANC versus time data is supported by the data and provides very good description of the mean tendencies as well as the variability seen in the raw data regardless the dosing schedule given to the patients. Individual profiles corresponding to panels 1,4 , and 5 shown in Fig. 3a show clearly the rebound phenomena during neutrophil recovery process controlled by the parameter $\gamma$.

The mean values for $\% \mathrm{G} 4$, mean ANC at nadir and mean time to nadir obtained from the numerical predictive check $\left(14 \%, 2.1 \times 10^{9} / \mathrm{L}\right.$, and 10 days) were very similar to those obtained from the observed profiles (18\%, $2.15 \times 10^{9} / \mathrm{L}$, and 9.5 days, respectively), providing additional support for the selected model.
Model-based simulations to support clinical development

Sim I Table 2 lists a summary of the results for this set of simulations. As expected all DLT doses showed greater toxicity than MTD. $\mathrm{A}_{\mathrm{High}}$ and $\mathrm{C}_{\mathrm{High}}$ show results of $\% \mathrm{G} 4$ and $\% \mathrm{G} 4>7$ days greater than 26 and $10 \%$, respectively. $\mathrm{B}_{\mathrm{High}}$ shows slightly greater toxicity than $\mathrm{A}_{\text {Low }}$. On the other hand, \%G4 and \%G4 $>7$ days were below 22 and $8 \%$ for all MTD. Another expected result is the delay in achieving the nadir and the time to recover found in $\mathrm{C}_{\mathrm{Low}}$ and $\mathrm{C}_{\mathrm{High}}$. Regarding $T_{\text {nadir }}$ and $T_{\text {recover }}$, no differences were found between low and high doses in any of the three schedules

Sim II For all the administration schedules simulated and considering cycles of 3 weeks, \%G4 did not increase during the second and third administration cycles compared to cycle 1 indicating that a 3 week period is at least sufficient to recover from BI 2536 neutropenic effects. Similar results than for the 3 weeks cycle were found for Schedules $A_{\text {Low }}$ and $A_{\text {High }}$ and Schedules $B_{\text {Low }}$ and $B_{\text {High }}$ when cycle duration was reduced to 2 weeks opening the possibility for these particular dosing schedules to increase patients' exposure to BI 2536 without compromising neutropenia. For the other schedule $\left(\mathrm{C}_{\mathrm{Low}}, \mathrm{C}_{\mathrm{High}}\right)$ a reduction of the cycle duration to 2 weeks led to an increase in $\% \mathrm{G} 4$ of 9-15\%. All those results are displayed in Fig. 4a

Sim III Figure $4 \mathrm{~b}$ shows the profiles corresponding to three dose levels. The plot shows also the impact of interpatient variability and uncertainty in model parameters. Simulations show that the $\% \mathrm{G} 4$ was always less than $30 \%$ for baseline ANC levels greater than $10 \times 10^{9}$ cells $/ \mathrm{L}$. Baseline ANC levels of $4-6 \times 10^{9}$ cells $/ \mathrm{L}$ resulted in $\% \mathrm{G} 4$ greater than $30 \%$ for the $300 \mathrm{mg}$ dose and the ANC levels of $2-3 \times 10^{9}$ cells/L resulted in $\% \mathrm{G} 4$ greater than $30 \%$ for doses greater than $200 \mathrm{mg}$. Those results suggest that baseline ANC might be considered when dosing BI 2536

\section{Discussion}

This study provides the first population PK-neutropenic response model for the Plk-1 inhibitor BI 2536 in patients with cancer. BI 2536 pharmacokinetics were described by a 
Fig. 3 a ANC versus time profiles for eight randomly selected patients. Symbols, individual values; grey solid lines, individual model predictions; dashed lines, typical population model predictions. b Results from the visual predictive check. Solid lines represent the median profiles, shadowed areas cover the $90 \%$ of the simulated ANC values
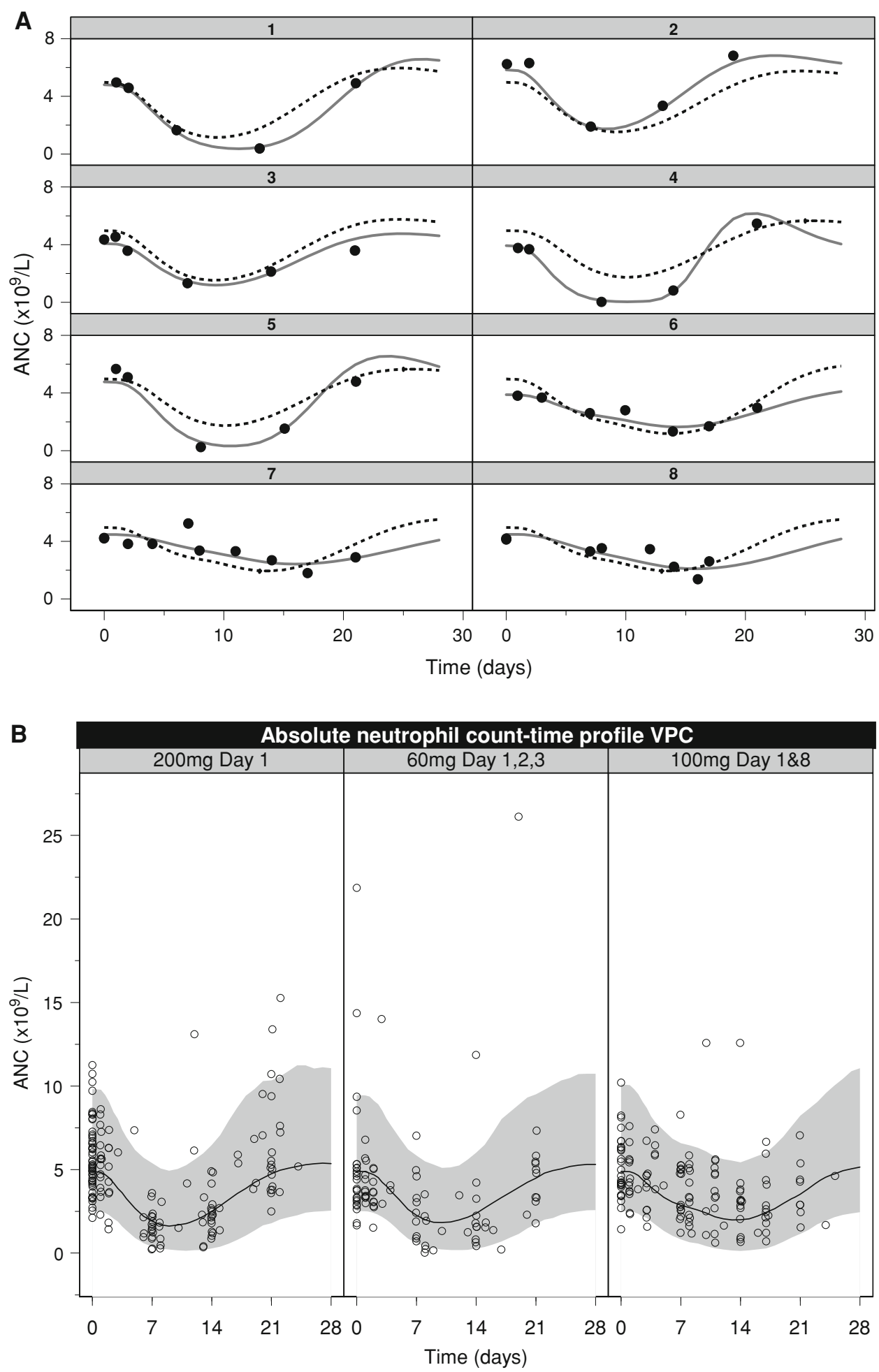

three-compartment model for which the total apparent volume of distribution calculated as the sum of $V_{1}, V_{2}$, and $V_{3}$ is about $1,600 \mathrm{~L}$, which greatly exceeded the real physiologic body volume, suggesting a significant distribution into tissues. The degree of unexplained variability associated with CL for BI 2536 (49\%) is within the observed range (14-60\%) of compounds that are currently being used or tested in cancer therapy: trabectedin, diflomotecan, docetaxel, epirubicin, pemetrexed [14-16, 19, 26]. The terminal elimination half-life was about $20 \mathrm{~h}$. 
Table 2 Results from the simulations corresponding to the MTD and DLT doses administration schedules

\begin{tabular}{llllr}
\hline Administration schedule & $T_{\text {nadir }}$ & $T_{\text {recover }}$ & $\%$ G4 & $\%$ G4 $>7$ days \\
\hline $\mathrm{A}_{\text {Low }} ; 200 \mathrm{mg}$ day $1^{\mathrm{a}}$ & $10(9.3-10.5)$ & $21(19.0-22.0)$ & $21(13-29)$ & $6(2-12)$ \\
$\mathrm{A}_{\text {High }} ; 250 \mathrm{mg}$ day $1^{\mathrm{b}}$ & $10(9.6-10.9)$ & $21(19.8-22.0)$ & $28(19-37)$ & $10(5-16)$ \\
$\mathrm{B}_{\text {Low }} ; 60 \mathrm{mg}$ days 1,2 , and $3^{\mathrm{a}}$ & $11(10.1-11.3)$ & $22(20.7-22.8)$ & $17(10-25)$ & $5(1-9)$ \\
$\mathrm{B}_{\text {High }} ; 70 \mathrm{mg}$ days 1,2 , and $3^{\mathrm{b}}$ & $11(10.2-11.4)$ & $22(20.7-22.6)$ & $22(15-29)$ & $7(3-12)$ \\
$\mathrm{C}_{\text {Low }} ; 100 \mathrm{mg}$ days 1 and $8^{\mathrm{a}}$ & $15(14.6-15.5)$ & $26(25.3-26.9)$ & $14(7-21)$ & $7(2-13)$ \\
$\mathrm{C}_{\text {High }} ; 150 \mathrm{mg}$ days 1 and $8^{\mathrm{b}}$ & $15(14.8-15.8)$ & $26(25.7-26.9)$ & $27(17-37)$ & $17(8-26)$ \\
\hline
\end{tabular}

$T_{\text {nadir }}$ time to nadir, $T_{\text {recover }}$, time to recover baseline, $\% G 4$ percentage of patients developing grade 4 neutropenia, $\% G 4>7$ days percentage of patients developing grade 4 neutropenia for more than 7 days

${ }^{\text {a }}$ MTD (maximum tolerated dose) for the investigated schedule

${ }^{\mathrm{b}}$ Dose where DLT (dose-limiting toxicity) occurred for the investigated schedule

BI 2536 showed linear PK properties within the dose range studied, and demographics such as total body weight, BSA, and gender did not show any significant covariate effect.

The time course of the neutrophil counts after the administration of BI 2536 was adequately described by the semi-mechanistic model previously proposed by Friberg et al. [9]. The estimates of the system related parameters $\left(\operatorname{Circ}_{0}=4.96\right.$ cells $\times 10^{9} / \mathrm{L}, \quad$ MTT $=4.45$ days, $\quad$ and $\gamma=0.161)$ and their IPV estimates were very similar to those reported during the last 7 years for a variety of different anticancer drugs on the market or in development: 4.46-5.81 × 109 cells/L for $\mathrm{Circ}_{0}, 3.65-5.62$ days for MTT and $0.119-0.23$ for $\gamma[9,12-14,17-19]$. The model selected in the current analysis is well established and has shown consistency in the system related parameter across several studies involving different anti-cancer drugs [14-17].

The inter-patient variability of the slope parameter was high $(65 \%)$ for BI 2536, however, the value was within the range reported for other anticancer drugs: $40-82 \%[9,12$, $14,16-18]$.

Results obtained from the covariate analyses showed that dosing schedule, gender and BSA elicited significant decreases in $-2 \mathrm{LL}$ with marginal reduction in IPV, when they were incorporated as covariates for the parameter slope. Simulations showed that the impact of the different schedules was negligible. Several authors have suggested that female gender is among others a significant predictor of neutropenia and is considered a risk factor in the Guidelines for the use of Colony-Stimulating factors in Managing Neutropenia [27]. However, gender was not found as a clinically relevant covariate in PK/PD models for neutropenia although a statistical significance was shown $[19,28]$. For BI 2536, the gender and BSA effects were not supported by recent data obtained in a Phase II study (data not shown) and therefore dose adjustment due to gender or BSA is not warranted.
From the results of the simulations Sim I-Sim III, the following practical information with regard to optimisation of the clinical development of BI 2536 can be extracted:

(1) All the MTD administration schedules $\left(A_{\text {Low }}, B_{\text {Low }}\right.$ and $\mathrm{C}_{\text {Low }}$ ) elicited an acceptable risk of neutropenia with values of $\% \mathrm{G} 4$ and $\% \mathrm{G} 4>7$ days less than 21 and $7 \%$.

(2) In addition, for the administration schedules of a single $60 \mathrm{~min}$ infusion at day 1 (Schedule A) and at days 1,2 , and 3 (Schedule B) the value of $\% \mathrm{G} 4 \mathrm{did}$ not increase considerably $(>5 \%)$ when cycle duration was reduced to 2 weeks facilitating to increase patients' exposure to BI 2536 without increasing the risk of neutropenia. This was not the case for Schedule $\mathrm{C}$ where the increase in $\% \mathrm{G} 4$ for the 14 days cycles was greater indicating a higher risk of neutropenia.

The administration of a single $200 \mathrm{mg}$ dose per cycle with a reduced cycle length of 2 weeks seem to be the most promising to test in further clinical trials with BI 2536 because the percentage of patients developing grade 4 neutropenia does not increase when reducing the cycle duration and it does not present a \% G4 as high as the single $250 \mathrm{mg}$.

(3) Results suggest that baseline ANC should be considered when dosing BI 2536 in terms of safety.

It is important to mention that those findings are based on model parameters obtained from only the first cycle of treatment assuming therefore no cumulative effect of the drug during consecutive cycles of treatment. Further clinical studies to investigate this assumption are required.

To summarise, a semi-mechanistic PK-neutropenic response model for BI 2536 was successfully applied. The model was used for various simulations and appeared to be a very helpful tool to support further clinical drug 
Fig. 4 Results from simulations. a Change in percentage of patients developing neutropenia grade 4 at nadir per administration schedule when treatment cycle is shortened from 21 to 14 days. percentile. b Relationship between ANC at baseline and the percentage of patients developing neutropenia grade 4 at nadir for BI 2536 doses of 100, 200, and $300 \mathrm{mg}$ administered as a $1 \mathrm{~h}$ intravenous infusion; shadowed areas cover the $90 \%$ of the calculated percentages Lines indicate the $95 \%$
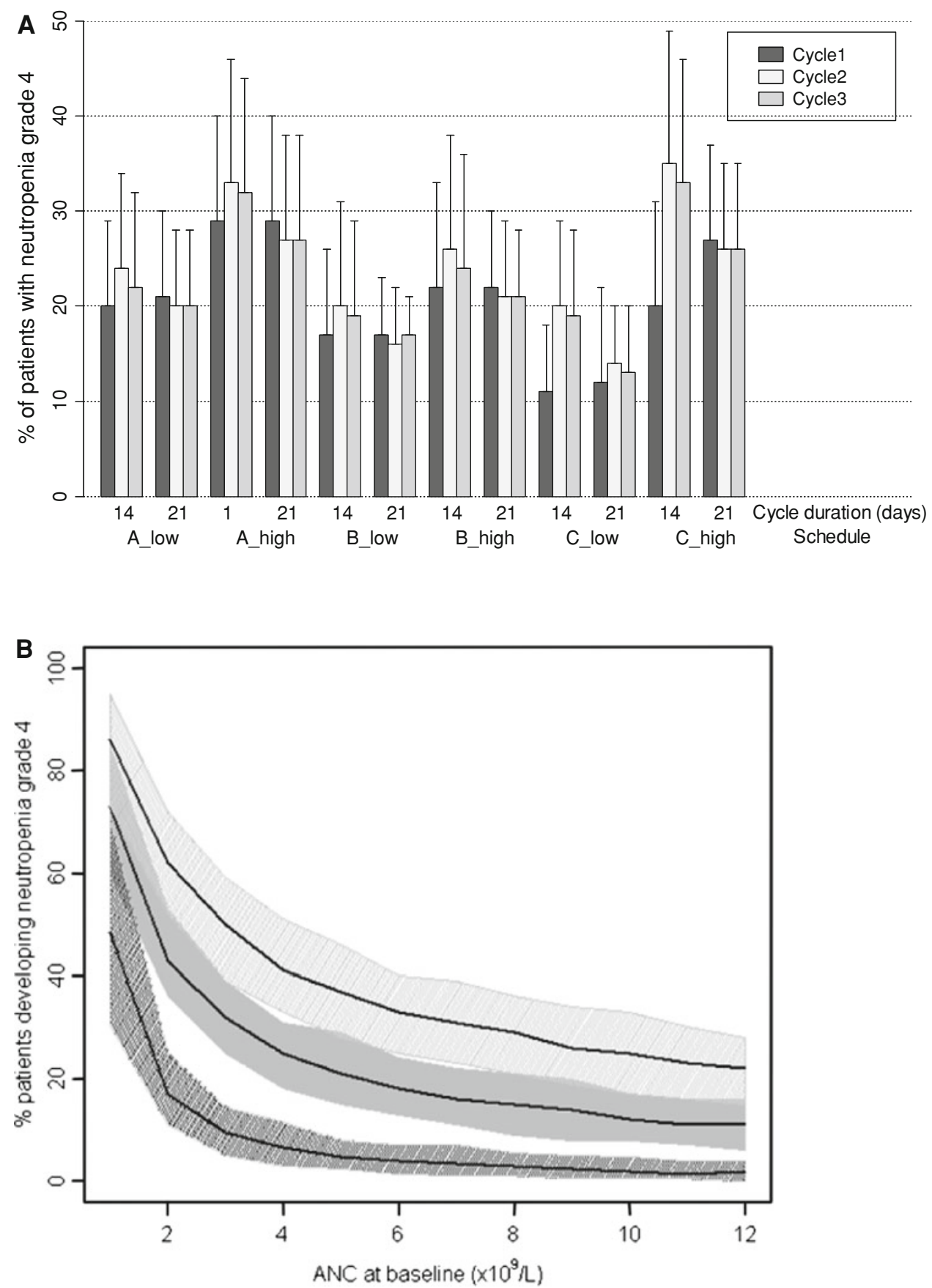

development. In particular, to explore the convenience of reducing the dosing interval from 3 to 2 weeks (assuming that it would increase the chance of showing tumour response), and the possibility to individualise the dose based on the ANC level at the start of the treatment.

Acknowledgments Dr. Martina Wein, Department of Pharmacokinetics and Drug Metabolism, Boehringer Ingelheim Pharma GmbH \& Co. KG

Funding Elena Soto and Iñaki F. Trocóniz have received financial research support from Boehringer Ingelheim Pharma GmbH \& Co.
KG; Alexander Staab, Christiane Tillmann, Dirk Trommeshauser, Holger Fritsch, and Gerd Munzert are employees of Boehringer Ingelheim Pharma GmbH \& Co. KG.

\section{References}

1. Nigg EA (2001) Mitotic kinases as regulators of cell division and its checkpoints. Nat Rev Mol Cell Biol 2:21-32. doi: $10.1038 / 35048096$

2. Smits VA, Klompmaker R, Arnaud L, Rijksen G, Nigg EA, Medema RH (2000) Polo-like kinase-1 is a target of the DNA 
damage checkpoint. Nat Cell Biol 2:672-676. doi:10.1038/ 35023629

3. Steegmaier M, Hoffmann M, Baum A, Lenart P, Petronczki M, Krssak M, Gurtler U, Garin-Chesa P, Lieb S, Quant J, Grauert M, Adolf GR, Kraut N, Peters JM, Rettig WJ (2007) BI 2536, a potent and selective inhibitor of polo-like kinase 1, inhibits tumor growth in vivo. Curr Biol 17:316-322. doi:10.1016/j.cub.2006. 12.037

4. Mross K, Frost A, Steinbild S, Hedbom S, Rentschler J, Kaiser R, Rouyrre N, Trommeshauser D, Hoesl CE, Munzert G (2008) Phase I dose escalation and pharmacokinetic study of BI 2536, a novel Polo-like kinase 1 inhibitor, in patients with advanced solid tumors. J Clin Oncol 26:5511-5517. doi:10.1200/JCO.2008.16. 1547

5. Marangolo M, Bengala C, Conte PF, Danova M, Pronzato P, Rosti G, Sagrada P (2006) Dose and outcome: the hurdle of neutropenia (Review). Oncol Rep 16:233-248

6. Rombout F, Aarons L, Karlsson M, Man A, Mentre F, Nygren P, Racine A, Schaefer H, Steimer JL, Troconiz I, van Peer A, COST B15 Experts (2004) Modelling and simulation in the development and use of anti-cancer agents: an underused tool? J Pharmacokinet Pharmacodyn 31:419-440

7. Minami H, Sasaki Y, Saijo N, Ohtsu T, Fujii H, Igarashi T, Itoh K (1998) Indirect-response model for the time course of leukopenia with anticancer drugs. Clin Pharmacol Ther 64:511-521. doi: 10.1016/S0009-9236(98)90134-5

8. Zamboni WC, D'Argenio DZ, Stewart CF, MacVittie T, Delauter BJ, Farese AM, Potter DM, Kubat NM, Tubergen D, Egorin MJ (2001) Pharmacodynamic model of topotecan-induced time course of neutropenia. Clin Cancer Res 7:2301-2308

9. Friberg LE, Henningsson A, Maas H, Nguyen L, Karlsson MO (2002) Model of chemotherapy-induced myelosuppression with parameter consistency across drugs. J Clin Oncol 20:4713-4721

10. Panetta JC, Kirstein MN, Gajjar AJ, Nair G, Fouladi M, Stewart CF (2003) A mechanistic mathematical model of temozolomide myelosuppression in children with high-grade gliomas. Math Biosci 186:29-41

11. Woo S, Krzyzanski W, Jusko WJ (2008) Pharmacodynamic model for chemotherapy-induced anemia in rats. Cancer Chemother Pharmacol 62:123-133. doi:10.1007/s00280-007-0582-9

12. Leger F, Loos WJ, Bugat R, Mathijssen RH, Goffinet M, Verweij J, Sparreboom A, Chatelut E (2004) Mechanism-based models for topotecan-induced neutropenia. Clin Pharmacol Ther 76:567578. doi:10.1016/j.clpt.2004.08.008

13. van Kesteren C, Zandvliet AS, Karlsson MO, Mathot RA, Punt CJ, Armand JP, Raymond E, Huitema AD, Dittrich C, Dumez H, Roche HH, Droz JP, Ravic M, Yule SM, Wanders J, Beijnen JH, Fumoleau P, Schellens JH (2005) Semi-physiological model describing the hematological toxicity of the anti-cancer agent indisulam. Invest New Drugs 23:225-234. doi:10.1007/s10637005-6730-3

14. Troconiz IF, Garrido MJ, Segura C, Cendros JM, Principe P, Peraire C, Obach R (2006) Phase I dose-finding study and a pharmacokinetic/pharmacodynamic analysis of the neutropenic response of intravenous diflomotecan in patients with advanced malignant tumours. Cancer Chemother Pharmacol 57:727-735. doi:10.1007/s00280-005-0112-6
15. Sandstrom M, Lindman H, Nygren P, Lidbrink E, Bergh J, Karlsson MO (2005) Model describing the relationship between pharmacokinetics and hematologic toxicity of the epirubicindocetaxel regimen in breast cancer patients. J Clin Oncol 23:413421. doi:10.1200/JCO.2005.09.161

16. Sandstrom M, Lindman H, Nygren $P$, Johansson M, Bergh J, Karlsson MO (2006) Population analysis of the pharmacokinetics and the haematological toxicity of the fluorouracil-epirubicincyclophosphamide regimen in breast cancer patients. Cancer Chemother Pharmacol 58:143-156. doi:10.1007/s00280-005$0140-2$

17. Latz JE, Karlsson MO, Rusthoven JJ, Ghosh A, Johnson RD (2006) A semimechanistic-physiologic population pharmacokinetic/pharmacodynamic model for neutropenia following pemetrexed therapy. Cancer Chemother Pharmacol 57:412-426. doi:10.1007/s00280-005-0077-5

18. Ozawa K, Minami H, Sato H (2007) Population pharmacokinetic and pharmacodynamic analysis for time courses of docetaxelinduced neutropenia in Japanese cancer patients. Cancer Sci 98:1985-1992. doi:10.1111/j.1349-7006.2007.00615.x

19. Hing J, Perez-Ruixo JJ, Stuyckens K, Soto-Matos A, LopezLazaro L, Zannikos P (2008) Mechanism-based pharmacokinetic/ pharmacodynamic meta-analysis of trabectedin (ET-743, Yondelis) induced neutropenia. Clin Pharmacol Ther 83:130-143. doi: 10.1038/sj.clpt.6100259

20. Friberg LE, Sandstrom M, Karlsson MO (2009) Scaling the time-course of myelosuppression from rats to patients with a semi-physiological model. Invest New Drugs. doi:10.1007/ s10637-009-9308-7

21. Beal SL, Sheiner LB (1989-2006) NONMEM users guides. Icon Development Solutions, Ellicot City

22. Ludden TM, Beal SL, Sheiner LB (1994) Comparison of the Akaike information criterion, the Schwarz criterion and the F test as guides to model selection. J Pharmacokinet Biopharm 22:431445

23. Mandema JW, Verotta D, Sheiner LB (1992) Building population pharmacokinetic-pharmacodynamic models. I. Models for covariate effects. J Pharmacokinet Biopharm 20:511-528

24. Jonsson EN, Karlsson MO (1999) Xpose-an S-PLUS based population pharmacokinetic/pharmacodynamic model building aid for NONMEM. Comput Methods Programs Biomed 58:51-64

25. Karlsson MO, Savic RM (2007) Diagnosing model diagnostics. Clin Pharmacol Ther 82:17-20. doi:10.1038/sj.clpt.6100241

26. Latz JE, Chaudhary A, Ghosh A, Johnson RD (2006) Population pharmacokinetic analysis of ten phase II clinical trials of pemetrexed in cancer patients. Cancer Chemother Pharmacol 57:401-411. doi:10.1007/s00280-005-0036-1

27. Lyman GH, Lyman CH, Agboola O (2005) Risk models for predicting chemotherapy-induced neutropenia. Oncologist 10:427-437. doi:10.1634/theoncologist.10-6-427

28. Kloft C, Wallin J, Henningsson A, Chatelut E, Karlsson MO (2006) Population pharmacokinetic-pharmacodynamic model for neutropenia with patient subgroup identification: comparison across anticancer drugs. Clin Cancer Res 12:5481-5490. doi: 12/18/5481[pii];10.1158/1078-0432.CCR-06-0815

29. Karlsson M, Holford NH (2008) A tutorial on visual predictive checks, p 17, Abstr 1434. www.page-meeting.org/?abstract=1434 